América sin Nombre, n. ${ }^{\circ} 23$ (2018): 59-72

DOI 10.14198/AMESN.2018.23.04

ISSN: 1577.3442 / eISSN: 1989-9831

Fecha de recepción: 05/06/2018

Fecha de aceptación: 03/07/2018
Modo de citación de este artículo:

Fernández Granados, Jorge. «De los pioneros a los epígonos». Madurez de la joven poesía mexicana. Alejandro Higashi e Ignacio Ballester (coordinadores). América sin Nombre, 23 (2018): 59-72, DOI: 10.14198/ AMESN.2018.23.04

Link para este artículo: http://dx.doi.org/10.14198/AMESN.2018.23.04

\title{
De los pioneros a los epígonos
}

\author{
From the pioneers to the epigones
}

\author{
Jorge Fernández Granados* \\ Sociedad General de Escritores de México
}

\section{Resumen}

Balance crítico de las antologías de poesía mexicana publicadas en los últimos años. Se toma como paradigma metodológico en este género la antología Asamblea de poetas jóvenes de México, publicada en 1980 por Gabriel Zaid, para a partir de ella comparar los diversos alcances y los verdaderos objetivos que inciden en la mayoría de las obras de este tipo. Se ofrece al final una exhaustiva bibliografía y hemerografía del caso. La parte medular del ensayo se propone revisar el papel del antólogo, el de las instituciones académicas y el de los programas del Estado para promover a los jóvenes autores. Ante todo, se discute el problemático lugar de la crítica en el panorama de la actual poesía mexicana.

Palabras clave: poesía mexicana, antologías, canon, crítica literaria, Gabriel Zaid

\begin{abstract}
Critical balance of Mexican poetry anthologies published in recent years. As early as a methodological paradigm in this genre, the Asamblea de poetas jóvenes de México, anthology published in 1980 by Gabriel Zaid, considered a starting point to compare the different scopes and the real objectives that affect most of the works of this kind. At the end of the article, an exhaustive bibliography and papers on this matter is offered. The core part of the essay intends to review the role of the anthologist, academic institutions and State programmes to promote the young authors. First of all, the problematic place of criticism in the panorama of the current Mexican poetry is discussed.
\end{abstract}

Keywords: Mexican poetry, anthologies, canon, literary criticism, Gabriel Zaid

* Poeta, narrador y ensayista. Estudió Música y es colaborador de Biblioteca de México, La Jornada Semanal, Letras Libres, Poesía y Poética, y Viceversa. Fue becario del CME, 1988; del INBA, 1991; del FONCA, 1992 y 1997; y del SNCA, 2001. Ha recibido importantes galardones, entre los que destacan el Premio Internacional de Poesía Jaime Sabines 1995 por Resurrección, el Premio Nacional de Poesía Aguascalientes 2000 por Los hábitos de la ceniza o el Premio Iberoamericano de Poesía Carlos Pellicer para Obra Publicada 2008 por Principio de incertidumbre. Acaba de publicarse De vuelta a Xihualpa. Lecturas críticas en torno a la obra de Jorge Fernández Granados. 


\section{Versiones y subversiones del género antológico en la última poesía mexicana}

La continuidad en el horizonte de las antologías de poesía en México se problematiza a partir de la década de los años ochenta del siglo xx. Se han publicado muchas -al parecer demasiadas obras de este género; pero, paradójicamente, su profusión no ha resultado correlativa a su calidad. Sobre esta particular situación hay diversas opiniones, lo mismo de especialistas que de lectores perspicaces, que parecen coincidir en un tópico: la antología tal como la conocemos se ha ido convirtiendo paulatinamente de un riguroso instrumento de crítica literaria en una plataforma de promoción, especulación y empoderamiento. Con cierto tono desdeñoso, a ratos sarcástico, el investigador Samuel Gordon lo expone con estas palabras:

«Censos», «registros», «directorios», «obras de arte efímero", «asambleas convocadas para una sola vez», «instrumentos de trabajo", "testimonio que una generación hace de otra", o de lo que se trate o denomine, según la taxonomía de otros. La mayoría de esas dudosas formas de acreditación literaria que han sido la mayor parte de las antologías de poesía mexicana a lo largo del siglo xx parecen, en muchos casos, no haber pasado de vulgares ejercicios de promoción grupal o, peor aún, de ser «antilogías» por cuanto sugieren, las más de las veces, haberse elaborado "en contra de» antes que para «mostrar» $\mathrm{o}$ «revelar a». En ocasiones, y con la misma sorna, la jerga literaria ha llegado a acuñar vocablos más peyorativos como el de «antojologías» -es decir, seleccionar «lo que se me antoja»- que junto con las «antilogías» se integran a esta categorización de trabajos caóticos, carentes, casi en su mayoría, de todo método o criterio congruente (112).

Un poco a rajatabla, este juicio puede parecer duro pero también pone sobre la mesa un peculiar estado de cosas dentro de este tipo de publicaciones. ¿Qué ha sucedido en los últimos años para radicalizar de esta manera las opiniones?

De entrada, conviene situar, así sea someramente, el entorno cultural de este último periodo. Irreversibles transformaciones que no hay que soslayar han modificado sin duda la realidad inmediata. De tal suerte que al comenzar el presente siglo una serie miscelánea de factores inciden en este nuevo escenario: un contexto demográfico multitudinario y prácticamente inabarcable, refinados programas estatales de estímulo para las actividades culturales a todos niveles, fragmentación y coexistencia de discursos poéticos extremadamente disímiles y en ocasiones incompatibles entre sí, guerras cifradas entre grupos y capillas literarias, políticas editoriales con vistas prioritarias al mercado, nuevas tecnologías de la información y cambios significativos en la relación entre autor y lector, así como una larga secuencia más de factores que no es el caso pretender agotar aquí. La suma de todo ello no forzosamente aportará una explicación concluyente, pero con seguridad dará las pistas para comenzar a entender la presente situación.

El punto de inflexión que dio lugar a este nuevo escenario en la actividad poética en México parece situarse entre 1982 y 1985; concretamente entre la severa crisis económica que tuvo lugar a principios de aquella década (y que no sería sino la primera de una serie de crisis más, recurrentes, hasta finalizar el siglo) y los históricos terremotos que devastaron la capital del país en septiembre de 1985. No afirmo en modo alguno que estos eventos fueran la causa de una peculiar circunstancia social o cultural, sino sólo que, de alguna manera, el final de una época y el principio de otra en la historia moderna de la sociedad mexicana se dio lugar ahí. Los años ochenta fueron una época de contrastes. Entre el final de la Guerra Fría, el ascenso del neoliberalismo y la brecha cada vez más consolidada entre el mundo desarrollado y el subdesarrollado, lo que sucedía en la microhistoria local no era -no podía ser, por supuesto- ajeno o indiferente a las grandes corrientes que modelaban el nuevo orden tecno-global que ya se abría paso inexorablemente por todos los rincones del planeta desde entonces. Para la clase media mexicana por lo menos el fin de la bonanza que había traído consigo el petróleo y un periodo relativamente estable de crecimiento económico finalizó, como un duro despertar, a mediados de aquella década. La desenfadada vitalidad de la generación que vivió su juventud hacia 1968 pasó a convertirse, en un lento pero evidente declive, en una austera sobrevivencia del día a día. Por necesidad más que por conveniencia, fueron tomando forma otros órdenes de relación entre los individuos, otros emergentes códigos y distribuciones del trabajo, otros modos de organización y de alianzas entre personas que, muy probablemente en otras circunstancias, no habrían actuado de aquella manera. Al parecer el epicentro tuvo lugar en 1985, no por un aislado evento telúrico sino, tal como lo registra Carlos Monsiváis, por el despertar de nuevas relaciones e iniciativas hasta entonces no atestiguadas entre los integrantes de la sociedad: 
El 19 de septiembre de 1985 la Ciudad de México experimenta un terremoto de consideración que causa un gran número de muertos (las cifras de las autoridades jamás se establecen con seriedad, los damnificados acercan el número a veinte mil fallecidos). Al día siguiente otro terremoto (o temblor) de menor intensidad reanuda el pánico y vigoriza el ánimo solidario. El miedo, el terror por lo acontecido a los seres queridos y las propiedades, la pérdida de familias y amigos, los rumores, la desinformación y los sentimientos de impotencia, todo -al parecer de manera súbita- da paso a la mentalidad que hace creíble (compartible) una idea hasta ese momento distante o desconocida: la sociedad civil, que encabeza, convoca, distribuye la solidaridad.

[...]

Sin debates previos, sin precisiones conceptuales, en cuatro o cinco días se impone el término sociedad civil, lo que, por el tiempo que dure, le garantiza a sus usuarios un espacio de independencia política y mental. Como es previsible, el impulso genera la pretensión de "cogobierno» en el empeño de salvar vidas y de restaurar o instaurar el orden urbano. En rigor, nunca son gobierno, pero esta creencia ilumina algo muy característico de los gobernantes: su rotunda banalidad. Ésta es la gran certeza de 1985: el descubrimiento de que la colectividad sólo existe con plenitud si intensifica los deberes y anula los derechos. Si la sociedad civil es una idea todavía imprecisa, los cientos de miles que se consideran sus representantes le otorgan energía y presencia irrebatibles (9-10).

Los alcances de la inestabilidad y la era de crecientes reacomodos que se han dado desde entonces apenas van siendo evaluados en toda su magnitud. Poco a poco, con el surgimiento de estudios y retrospectivas que analizan lo acontecido de aquel periodo en adelante, la perspectiva disponible se va clarificando. Hoy está claro, por lo menos, que no fue aquel un mero periodo de disminución en la actividad editorial ni un momento de amodorrado relevo generacional. Hubo en realidad un colapso sin precedentes de estructuras productivas, educativas y culturales.

La vertiginosa fiesta juvenil -o el fenómeno demográfico-literario, como se quiera considerarque Gabriel Zaid había capturado en la Asamblea de poetas jóvenes de México parecía haberse desvanecido hacia mediados de la década siguiente. La crisis fue imponiéndose como medio ambiente natural y la dispersión prevalecía una y otra vez ante las débiles y no muy numerosas iniciativas de cohesión. No obstante, la actividad poética vivió, durante aquellos años, aparentemente en un cuartel de invierno. Si bien disminuyeron las manifestaciones públicas de la literatura, las copiosas y baratas ediciones al alcance de amplios sectores, las revistas culturales, los prestigiosos encuentros internacionales y, en general, todas las actividades que suponían solventes presupuestos, varios de los autores de la Asamblea de poetas jóvenes de México siguieron escribiendo y fue aquel su periodo de cenital madurez; otros, como era previsible y hasta necesario, dejaron de lado el oficio de la literatura.

Fue también a partir de la década de los años ochenta del siglo xx durante la cual, en las más relevantes -o por lo menos en las más citadas- antologías que se realizaron posteriormente a la Asamblea... ${ }^{1}$ de Gabriel Zaid un puñado de aspectos han ido tomando preeminencia. Tales aspectos son primordialmente de orden metodológico y bien podrían obedecer a un cambio en la correlación entre objetivos e instrumentos disponibles; pero no hay que descartar que también pueden ser evidencia de la mutación generacional tanto de los compiladores como de los potenciales lectores. Israel Ramírez los fija en cinco principales:

Los cinco aspectos principales que se desprenden del análisis de ellas son: el creciente auge de poetas, la dificultad de selección crítica, la centralidad de la juventud como campo de estudio literario en la etapa reciente, la necesidad de configurar nuevos moldes críticos para estudiar las promociones poéticas y la consolidación de las décadas como criterio para distinguirlas (442).

No es, claro está, que dichos aspectos estuvieran ausentes en las compilaciones anteriores, sino que al parecer a partir de entonces presiden el programa antológico. Es decir, estos aspectos se tornan no sólo presentes sino dominantes en las premisas de este género de publicaciones. Es así que puede detectarse la continuidad de tales aspectos en prácticamente todas las antologías de los últimos treinta años. Llama la atención la reiterativa fórmula de estos paradigmas en ellas: «auge de poetas», "centralidad de la juventud», «necesidad de nuevos moldes críticos» y la conformidad en acatar el "criterio de las décadas para distinguirlos». Ha sido tal la multiplicación

1. Al final se ofrece una relación detallada de antologías, muestras y panoramas de poesía mexicana publicados después de 1980. 
editorial de obras tan semejantes unas a otras y la persecución casi mecánica de los anteriores aspectos en su formulación que detenerse específicamente en cualquiera de ellas descaminaría engañosamente el objetivo crítico hasta aquí proseguido.

Sin embargo, más allá de estos aspectos recurrentes y los reacomodos demográficos que probablemente los propician, más allá de la curva malthusiana de estas nóminas generacionales, más allá de la espiral de las crisis y los repuntes económicos, se atestigua un fenómeno de utilitarismo bajo la mayoría de las compilaciones antológicas de las últimas tres décadas. Como se apuntó un poco más arriba: la antología parece haberse convertido de un riguroso instrumento de crítica literaria en una plataforma de promoción y especulación. En un afilado artículo, Sergio Cordero lo resume así:

En los ochenta, se publicaron muchas antologías que pretendieron actualizar la nómina de poetas incluida en la célebre obra de Alí Chumacero, Octavio Paz, José Emilio Pacheco y Homero Aridjis Poesía en movimiento (1966). En realidad, lo que estas antologías revelaron es que sus autores, más que actualizar el panorama de la poesía mexicana, estaban interesados en utilizar la antología en sí como herramienta de poder cuya autoridad debían acatar los poetas no contemplados dentro de la selección (54).

Podría estar aquí el dedo en la llaga. No sería explicable dicha proliferación editorial sin una motivación lo suficientemente poderosa como para desencadenar este "frenesí antológico». La razón de fondo bien podría estar en la soterrada disputa por una posición de particular influencia, es decir, por una ventajosa posición de poder. Poder, se entiende, evidentemente literario, pero también poder por cuanto significa el acceso a formas de promoción y reconocimiento, así como el intercambio de prerrogativas y alianzas estratégicas, en suma: bonos especulativos dentro de una bolsa de valores imaginaria. Las antologías representan visibilidad y, por lo mismo, sitúan en el panorama hipotético de la literatura no tanto la obra como el nombre de los autores en ellas incluidos. De hecho, y tratándose concretamente de autores jóvenes, la obra es aún inexistente; por lo que todo su crédito se basa en un puro potencial. Esta situación ha llegado a extremos paródicos en nuestros días:

En la primera década del siglo XXI, este frenesí antológico llegó a un grado de saturación: cada pequeño grupo de escritores había publicado su propia selección en respuesta a (iba a escribir: «para vengarse de») otra compilación previa. He denominado a esta patología «El síndrome Maples Arce» (Cordero 54).

Cordero alude a una anécdota que pinta muy bien hasta dónde pueden llegar los rencores literarios: como es sabido, una de las reacciones más antagónicas y frontales a la publicación en 1928 de la célebre Antología de la poesía mexicana moderna (realizada por el grupo Contemporáneos aunque firmada sólo por Jorge Cuesta) fue la edición, en Roma, doce años después, de otra antología exactamente con el mismo título, donde el poeta estridentista Manuel Maples Arce no sólo daba su propia versión del canon poético mexicano del mismo periodo, sino que abiertamente lo impugnaba burlándose de cada una de las opiniones de la primera.

$\mathrm{El}$ «frenesí antológico» no terminaría allí. Pronto se desbordaría a otros terrenos bajo la subespecie de «arte alternativo» y demostraría que no era una causa sino un efecto de otro fenómeno acaso más nocivo: la búsqueda a ultranza de lo novedoso. Lo novedoso no como lo genuinamente nuevo sino como lo vendiblemente remozado, cierta estrategia que confía de antemano en la ingenuidad o en la poca formación del público inmediato para producir un golpe de efecto, en apariencia original pero que rara vez resiste una segunda o tercera exposición (lectura, audición, representación, montaje, etc.). De tal suerte que cierta espectacularidad sin escrúpulos, efectista, sólo obediente a la pesca de la eficacia histriónica, se ofrece como valor inequívoco del presente:

Evidentemente, las antologías ya no fueron efectivas para conseguir el elogio (y la incondicionalidad) de los colegas y la admiración (que no la lectura desinteresada) del público. Buscando soluciones, los afectados no recurrieron a la más lógica (depurar el mensaje: escribir mejores libros), sino a la más espectacular (a falta de un mensaje de interés, apelar a medios más llamativos que el libro). De este sofisma surgieron los experimentos [...] donde se intenta estimular el interés por la poesía a través de "soportes performáticos»: se exhuman prácticas como escribir poemas sobre objetos o escribir poemas en forma de objeto y se agregan a estos procedimientos los nuevos recursos provenientes de la informática y los medios electrónicos (un ejemplo: los «videopoemas»). Por desgracia, ninguno de estos alardes logra desviar la atención del problema esencial: un mal poema sigue siendo malo, esté impreso en papel o en una oblea de cajeta, se 
presente en un libro o dentro de un espectáculo multimedia. Aunque la mona se vista de seda... (Cordero 55).

Así las cosas, el presente, para este como para otros géneros literarios y tradiciones, es lo mismo un simulacro que un mercado. En nuestros días la incontable mayoría de obras publicadas bajo el rótulo de antologías ha dado un giro de casi 180 grados con respecto a su punto de partida -el históricamente registrado, por lo menos-. Si en un principio fue la antología una acuciosa y atareada aspiración de ordenar, compendiar y transmitir un conocimiento o, por lo menos, un gusto emanado de un conocimiento, en la actualidad, en cambio, es evidente el imperativo impacto que las dirige, el programa de acreditación que en ellas subyace y, lo peor, que las requiere para atraer la atención sobre un público y un pequeño mercado, al parecer tan escépticos como agotados.

No hay que negarlo: casi nadie espera ya, al encontrar una nueva obra de este género entre las novedades del mes, otra cosa que un minoritario y dirigido mensaje en clave, o, en el mejor de los casos, un censo políticamente correcto y aparentemente democrático. Lo medular -el mensaje dentro de la botella en el mar editorial- es el índice, la casa editorial y algún prólogo que consigna la tesis (también cifrada) de quien ha llegado a la conclusión de que sin aquella antología no logrará ser nunca quien pretende ser. En suma: la razón de ser de las antologías pasó de un valioso peritaje literario a un mero oportunismo editorial.

\section{Compilaciones clónicas o acerca de la construcción artificial del prestigio}

Un fenómeno creciente en el actual contexto mexicano - pero tal vez no sólo allí- es lo que podría llamarse el laboratorio clónico o la manipulación especulativa del canon emergente. Analizando y comparando con cuidado ciertos ejercicios antológicos recientes se vuelve notable la inercia hasta cierto punto institucionalizante que los anima. Al parecer, ocurre por la multiplicación de panoramas, muestras y nóminas surgidas de la acumulación acrítica de opiniones más o menos clonadas unas de otras y la mayoría sin el elemento cardinal que da pie a un criterio propio: la experiencia individual de la lectura de la obra de cada autor.

Es verdad que el paso del tiempo o la distancia geográfica es un obstáculo determinante para leer de primera mano a los nuevos autores y, por lo mismo, para realizar una antología de lo distante en el espacio o en el tiempo en gran medida suele recurrirse al trabajo indirecto, es decir, como el propio Gabriel Zaid lo hizo en su momento, a elaborar una «antología de antologías». Particularmente en el caso de sondear nuevas generaciones el problema se agudiza: cientos de libros y plaquetas de poesía editados por instancias locales año con año, a lo largo de un país de más de ciento veinte millones de habitantes, convierte al precedente de la Asamblea de poetas jóvenes de México en un modelo irrepetible (o por lo menos tan costoso y demandante de trabajo y tiempo que nadie ha podido emular hasta la fecha). Suele acudirse entonces a las compilaciones regionales, o a las «nacionales» más o menos accesibles, cuando se pretende extraer panoramas de la poesía nueva. Al no disponer de la evidencia completa y directa de las obras, estos compiladores de segunda o tercera mano no hacen sino copiar, agregar o borrar nombres de los índices y recapturar poemas supuestamente representativos de sus autores. En la medida en que desconocen tanto dichas obras (aunque dan por un hecho su preeminencia) como las de otros poetas (tal vez de igual o mayor interés pero no citados en las compilaciones a su alcance) va prosperando perversamente la inercia de la que parece ser la poesía joven. Obviamente todo esto levanta un juego especulativo de la realidad literaria.

Resulta inherente a este método de compilación el incurrir en prejuicios y reiteraciones injustamente asentados, lo mismo que en desatinados olvidos. Tal vez porque parece siempre más fácil sumarse a la inercia de los prestigios que revisar palmo a palmo el terreno con el fin de enarbolar una opinión propia. De esta manera, el laboratorio clónico de las antologías trabaja regido por la conveniencia y la comodidad. No tiene intención de inventar ni descubrir nada, simplemente de "piratear» lo cercano, lo conveniente o lo vendible. Dentro de esta espiral lapidaria el prestigio sólo engendra más prestigio y el olvido, más olvido.

Tal mecanismo clónico entre las antologías, sin embargo, no es privativo de la poesía mexicana. Tanto la reiteración de la referencia prestigiada como la «confirmación del olvido» de gran número de autores se ha observado desde hace bastante tiempo en otras tradiciones. Uno de los más conspicuos especialistas en estos temas, José Francisco Ruiz Casanova, subraya este fenómeno y advierte su importancia en la interdependencia funcional entre antología y canon literario: 
[...] es el sentido de preservación, que es el de la propia escritura en cuanto tal, esencia del procedimiento antológico en tanto activación de la memoria pero también -y no menos cierto- en cuanto confirmación del olvido. Si la reiteración antológica lleva a autores y textos a un estatus de indiscutibles, por memorables, tal reiteración conlleva, de modo parejo, la reiteración -tantas veces- de los olvidos. Este es uno de los asuntos que deberá tratarse con detenimiento cuando se estudie la relación de la antología y el canon literario (46).

No es inexacto pensar, también, en cierto facilismo académico, escolar o de simple consumo; una necesidad -más o menos- urgente de información -más o menos- simplificada, pero sobre todo de acceso rápido. El género de la antología suele verse como compendio donde el conocimiento se halla sintetizado y se incurre así, por parte sobre todo de un público no especializado, en el error de suponer a esta clase de obras resúmenes imparciales para obtener mucha información literaria en poco tiempo, la suposición de que la antología cumple las veces de un manual de fácil acceso para incursionar en una materia cuya aparente complejidad desalienta al lector. Opina Alberto Vital a este respecto:

La vertiginosa multiplicación de ofertas literarias y la disminución del tiempo para toda lectura que no sea productiva a corto plazo, invitan a recibir cualquier visión panorámica y sinóptica como un paratexto informativo, [...] la mayoría de los lectores prefiere manejar (o cree que maneja) un texto que contenga el mayor número de información sumaria e intersubjetiva; en resumen: un texto donde el conocimiento se haya convertido en "cantidad de información» (101).

Por obvias razones, el considerar a cualquier antología un manual didáctico implica, a largo plazo, tanto la progresiva degradación informativa como formativa de los eventuales lectores, no digamos ya las impredecibles consecuencias que ello podría significar en el ámbito de la enseñanza o la docencia.

Sin embargo, para no faltar a la equidad, hay que tener en cuenta el otro brazo de la balanza: las antologías también pueden llegar a cumplir una función encauzadora y hasta propedéutica en algunos casos. No hay que olvidar que una de sus principales razones de existir fue -por lo menos en un principio- cierta finalidad instructiva. La idea de preservar y transmitir lo más significativo de una literatura en una forma portátil está en el origen mismo de su invención. Si bien es casi imposible separarlas de su consustancial componente de subjetividad, o de sus inevitables parcialidades en materia electiva y de gusto, también es cierto que este tipo de obras pueden ser válidos instrumentos para la divulgación literaria. Juan Domingo Argüelles -quien hay que reconocer que se ha destacado en años recientes por ofrecer ambiciosos, pero eficientes y balanceados proyectos antológicos- repasa este punto y toma por un momento el terreno de la contraparte para hacer la defensa de los intereses del «hipotético lector», que no tienen por qué ser ajenos en esta discusión:

Más que consentir a los autores, lo que busca toda antología es seducir y atrapar a los lectores. No hay otra razón para publicar una antología. Aun en el caso de que se tratara de una investigación histórica o filológica para el servicio exclusivo de estudiantes, estudiosos y el propio medio literario, si el destino no está entre el público en general, bastaría con imprimir unos pocos ejemplares o poner el archivo electrónico al alcance de esos específicos sectores. Publicar es otra cosa: es ofrecer al lector activo y al lector en potencia (al hipotético lector) una propuesta de lectura, una invitación a leer que, por supuesto, no concluye con la antología, sino que ahí empieza, para idealmente continuar con la búsqueda y la lectura de los libros de esos autores que cumplieron las expectativas (31).

Quedaría, ciertamente, esta idea a la par digna de consideración de la antología como punto de partida o seminario poético desde el cual algunos lectores emprenderían eventualmente la búsqueda y la lectura de los libros de aquellos autores que les hubiesen particularmente atraído. De ser así, tal compilación cumpliría una función divulgativa nada desdeñable.

Por otro lado, y también en otro orden, dos factores han venido en los últimos años a pulverizar y enrarecer más todavía estas inercias, dos factores en principio ajenos al ámbito literario, pero que por sus alcances y consecuencias han terminado por incidir vertebralmente en las actividades artísticas del país: por una parte, la presencia de un sofisticado mecenazgo del Estado y, por la otra, las nuevas tecnologías digitales en el manejo de la información.

Efectivamente, el auge y la sorprendente continuidad de algunas instituciones culturales surgidas a finales de los años ochenta ha tenido efectos contradictorios sobre la producción artística. $\mathrm{Si}$, por un 
lado, estas instancias gubernamentales han venido a representar un efectivo apoyo a muchas genuinas vocaciones creativas; por otro, fieles finalmente a su naturaleza burocrática, también han terminado por piramidar todo lo que tocan. Los programas de becas y estímulos a la cultura han logrado ser tan eficientes que han configurado casi una nueva clase social, una élite artística cuyos códigos de afianzamiento y promoción no coinciden necesariamente con los verdaderos méritos literarios. Aparecen de este modo un gran número de libros "estatutarios", que muy probablemente no habrían sido redactados ni publicados por la sola iniciativa de sus autores de no haber mediado una demanda institucional, curricular, que otorga a esas publicaciones cierto crédito creativo o, lo que ya resulta reprobable, cierta apariencia de trayectoria literaria destinada a obtener una escalada acumulativa de prebendas. Alejandro Higashi denomina a esta nueva identidad entre las generaciones emergentes el poeta-becario:

El poeta-becario, una figura de nuestra modernidad mexicana, pasa de ser un artista marginal a ser un creador en un proceso de profesionalización donde ya no solo necesita ser buen poeta, porque se le piden muchas otras credenciales: libros publicados, publicaciones en revistas prestigiosas y en antologías, premios, entrevistas, congresos para entrar en comunicación con profesionales de otras latitudes, lecturas públicas, trabajo social (en forma de talleres itinerantes), etcétera (53).

En su libro $P M / X X I / 360^{\circ}$. Crematística y estética de la poesía mexicana contemporánea en la era de la tradición de la ruptura, Higashi también plantea y tipifica lo que reconoce como una progresiva profesionalización del poeta dentro de una cada vez más refinada red burocrática. Esta profesionalización se origina principalmente por la participación del Estado como un omnipresente mecenazgo que, en los últimos años, se ha convertido en aquel ogro filantrópico que advirtió en su hora Octavio Paz.

La profesionalización quiere decir, para el caso, especialización de un discurso literario unido cada vez más estrechamente a un sistema estatal de subsidios. Puesto que quien elige y otorga tales subsidios es una comisión integrada por otros colegas igualmente especializados, el propio discurso literario va dirigido fundamentalmente a convencerlos. Tal profesionalización llega al punto de conformar desde el origen el producto del propio discurso para dirigirlo no a la finalidad de un potencial público receptor sino a las oportunidades curriculares que dicho discurso sea capaz de generar.

Si bien este proceso de profesionalización ha terminado por influir de una u otra manera en todos los creadores, es en las generaciones más jóvenes donde puede atestiguarse con plena amplitud sus consecuencias estéticas. La más notable de ellas es una imperiosa necesidad de crear cuanto antes una "marca registrada» que identifique su particular discurso en medio de una multitud de discursos competidores. El objetivo es "posicionar» una identidad en un virtual tablero de lucha curricular donde, por desgracia, cuenta menos la calidad que la visibilidad ${ }^{2}$.

Pasemos ahora al segundo factor que se ha señalado: el ascendente cambio de las tecnologías, los modos y los tiempos en que la información fluye y se asimila. Aunque esto no parece a primera vista un fenómeno directamente literario termina siéndolo: dentro de la provisionalidad mediática nada garantiza que el concepto de libro o de obra publicada tal como los concebimos hasta hoy seguirán consistiendo en un soporte de papel. Los materiales, las dimensiones y seguramente los alcances de este objeto cultural están ampliándose o transfigurándose de manera impredecible.

Para la poesía contemporánea la tecnología y sus redes digitales ofrecen un paraíso de lo instantáneo: la inmediatez de lo escrito y publicado, su testimonialidad en "tiempo real»; a semejanza de un ojo ubicuo o un ineludible oído que convierte la realidad, al momento y casi de modo automático, en documento público. Pero no debe pasarse por alto que quien de un lado y otro observa todo ello en el fondo es el mismo elusivo, contradictorio y ancestral desconocido: el lector. A todo ello hay que agregar que el medio electrónico no corrige ninguno de los vicios ya planteados; se limita a multiplicarlos y proseguirlos por otros canales.

Dado el presente contexto, la fisonomía del canon emergente se redistribuye de un día para otro; aunque tal vez lo que cambia con mayor caducidad son sus formulaciones -la señalada multiplicación de panoramas, muestras y nóminas, incluidos ahora

2. Para ahondar en este tema es ampliamente recomendable consultar la obra citada de Alejandro Higashi, PM / XXI / $360^{\circ}$. Crematistica y estética de la poesía mexicana contemporánea en la era de la tradición de la ruptura (2015), en particular el tercer capítulo: «Epigonismo, fratricidio y fondos públicos en la era de la tradición de la ruptura» (187-432). 
los electrónicos-. Atestiguando la muy improvisada metodología de este tipo de publicaciones, Samuel Gordon nuevamente reconviene:

Desde una perspectiva crítica responsable, se vuelve imperativo abandonar algunos conceptos anteriores. No podemos crear taxonomías, o aferrarnos a viejos criterios que han perdido hoy su operatividad, por necesidades de manejo de grandes cantidades de información reuniendo lo no unificable por la sola virtud de rotular panoramas críticos cuando los criterios grupales parecen no cumplir ya con sus cometidos (Gordon 124).

Son estos «criterios grupales» lo más evidente y lo menos defendible. Lo que se disputa al parecer en la actualidad ya no es la tradición ni el futuro de esa tradición. Se disputa el presente, sus favores y sus fines inmediatos, una posición política y un enmascarado tráfico de influencias. De ahí tal vez que hoy se vean esencialmente como publicidad las no pocas antologías que se publican cada año. El canon como mercadotecnia. Un mero hit parade literario. Imposible o incompatible, pues, creerlas trascendentes. La antología poco a poco dejó de ser un vehículo del canon para convertirse en un aparato de la promoción.

Este contradictorio cuadro de pugnas obliga al énfasis en el deslinde de estas dos especies que a veces se confunden: el canon y la antología. Si el canon poético, en su más vigente sentido, es tanto un severo edificio intelectual como un avatar colectivo de lecturas a lo largo de generaciones, no hay que evitar afrontar el hecho de que la antología, el género editorial que suele (sólo en apariencia) representarlo, es definitivamente otra cosa.

El canon es esencialmente un concepto literario, la antología es esencialmente un concepto editorial. Hay que entender también que una antología es un instrumento de la crítica literaria. Por eso es necesaria una competente crítica literaria para que surja una antología perdurable. Sólo será perdurable en este campo una obra que aporte una visión coherente y rigurosa de una literatura. No estamos ante un problema de creatividad poética, ni siquiera de autoridad intelectual, sino de crítica.

Valdría la pena detenerse un momento sobre esta progresiva extenuación o atenuamiento de la crítica. De ninguna manera puede suponerse que ha desaparecido, pues es consubstancial a la actividad misma de la lectura. Más bien se ha subsumido, se ha desplazado de un plano público a uno privado. Otro u otros condicionantes se ejercen sobre ella, al parecer, lo que termina maniobrando como un mecanismo extorsivo o, por lo menos, coercitivo. Opina Víctor Manuel Mendiola sobre este hecho:

Durante muchos años, en México no hubo dudas de cuáles eran los buenos libros y quiénes eran los buenos escritores, porque los artistas excelentes hacían crítica o, por lo menos, daban su opinión. Hoy la crítica parece estar disminuida $y$, en ocasiones, atrapada en los lazos de amistad o en los intereses de grupo. El análisis de una obra o el premio a un libro tiene, en ocasiones, más que ver con el conocimiento personal o con el lugar que ocupa un autor en los medios que con la originalidad de un texto (s. p.).

El juego de conveniencias, desde la valoración de Mendiola, «atrapa en los lazos de amistad o en los intereses de grupo» no sólo la exposición pública de los juicios sino el criterio personal ante las obras. En otras palabras: la firma pesa más que el texto. Pero esto sólo puede suceder en un ambiente enrarecido por un juego de fuerzas ajeno a la literatura misma. Un juego de fuerzas donde el mérito artístico ha sido sustituido por la oportunidad política. Más lapidariamente aún sobre este mismo punto, el ensayo preliminar que acompaña a la antología 359 Delicados (con filtro) lo consigna de la siguiente manera: «Lo que sí hay, sin embargo, y ese es el triste panorama que el país vende, es un sistema aceitado de elaboración de prestigios y de arrinconamientos silenciosos que no solo los escasos críticos, sino incluso los poetas, dócilmente parecen aceptar» (24).

Aunque en apariencia separados, los fenómenos que acabamos de señalar hasta aquí son convergentes: tanto el mecanismo clónico que insta a multiplicar las antologías poéticas bajo procedimientos acríticos, como la inercia en ellas de las famas y los olvidos, lo mismo que la eficiente y sostenida presencia de un nuevo mecenazgo del Estado, el cual ha logrado trastocar los comportamientos y las expectativas de la comunidad cultural, así como las emergentes tecnologías electrónicas en el manejo de la información $y$ un consecuente escenario que evidencia el juego de fuerzas soterradas donde el mérito artístico ha sido sustituido por la oportunidad mediática. No son todos estos, claro está, los únicos factores para hacer una evaluación de la situación dominante; pero es una evidencia palmaria de que hoy en día en México, en gran medida tras estos fenómenos, radica la efectiva construcción del prestigio literario. 
La posición y la responsabilidad del antólogo.

\section{Balance frente al futuro}

Tras toda antología, sin embargo, hay siempre una perspectiva y una expectativa personal. Las razones y las intenciones de quien la realiza son igualmente dignas de valoración, por cuanto revelan una parte si bien subyacente no menos significativa en los fines de este tipo de empresas. El antólogo en sí, como individuo o protagonista, así sea circunstancialmente, también obra bajo un objetivo lo suficientemente justificable para él, objetivo que a su vez determina su voluntad y no pocas horas de su trabajo y de su tiempo. Ahondar en sus motivaciones, en la esencia de sus expectativas, a veces largamente cultivadas, sin la rapidez de la descalificación o la condena, es por tanto un expediente necesario. Nuevamente Ruiz Casanova despeja con acuciosidad la motivación probablemente medular de quien se enfrasca en la realización de una antología:

Todo antólogo, sea cual sea su dedicación literaria o intelectual primera, siente la tentación de hacer autobiografía de sus lecturas, de su conocimiento de autores, obras y épocas y, sobre todo, de legar un modelo de lectura de la tradición (o del presente) que puede ser recibido como modelo de autoridad. En el fondo, aunque con menos probabilidades que las que puedan barajar obras y autores originales, el antólogo también persigue una suerte de posteridad, académica, filológica o historiográfica, y esto aunque sepa que tan buen punto inicia su obra, que dichas probabilidades son escasas o nulas, dada la ya casi verdad universal de que cada tiempo, cada lengua o cada cultura, levanta sus propias antologías (82).

Tras la expectativa del antólogo de legar un determinado modelo de lectura de la tradición hay también, como subraya Ruiz Casanova, un deseo, recóndito o asumido, de alzarse dentro de la literatura como un modelo de autoridad. Aquí es donde reside precisamente lo que podría llamarse la hybris del antólogo.

Vamos a ver: por rigurosas, rentables o «bienintencionadas» que sean, la mayor parte de las antologías ocultan su verdadera naturaleza: son a fin de cuentas un ejercicio de poder. Un sometimiento, disfrazado de gusto estético "personal, de grupo o bien desde un criterio histórico-, de una vasta realidad extensa, mayor y verdadera, a una realidad acotada, que supone no sólo contener o representar a aquélla sino corregirla. La antología dista de ser meramente una "opinión publicada» (algunos afirman esto a manera de descargo); se trata en realidad de una simbólica posición en una disputa de poder.

¿Cuáles son, específicamente, los mecanismos de poder que una antología conlleva? Sin dejar de reconocer, como he pretendido en este ensayo, sus excepciones, esto es, las genuinas empresas intelectuales y los valiosos instrumentos de crítica literaria que hay en algunas, observo tres constantes en casi todas ellas:

1. De entrada, su autor, o autores, incurren en un espejismo jerárquico: quien se propone como juez busca imponerse como depositario de la justicia. Aún en el caso de acertar en sus evaluaciones, es innegable que se parte de una sobrevaloración de la autoridad del propio juicio, la cual lleva - por ingenuidad, protagonismo o pura ambición- a confundirlo con la verdad. En otros términos, el más infantil de los sofismas: "lo que me gusta es bueno y es bueno porque me gusta».

2. El afianzamiento de un reducto doctrinario: nadie hace una antología contra sí mismo; por el contrario, suele ser una proyectiva apología. Lo que su autor afirma entre líneas con ella es entre otras cosas el árbol genealógico de su gusto (y de paso de su propia obra literaria, cuando ella existe). Aunque procure revestir esta doctrina de una desinteresada pasión crítica, obedece a una indirecta estrategia de legitimación.

3. Por último, la motivación menos sutil y más vulgar: figurar. Aparecer a como dé lugar en un escenario del que se teme ser excluido. Quien realiza una antología sabe que es otro modo de hacerse presente en un epicentro literario. Se adivina la doble moral del anfitrión: el único invitado sin invitación puesto que es el convocador del cónclave. Aún en el caso de no incluirse, es evidente que quien firma una obra de este género se ha incluido a sí mismo, desde una agazapada posición de autoridad.

Por lo demás, en la naturaleza misma de cualquier antología inevitablemente hay un criterio de valoración estética o bien de subjetividad, por más que quien selecciona pretenda mostrarse imparcial o incluyente. No es ninguna novedad advertir que quien elige siempre elige lo que le gusta o conviene, y por lo tanto elegirá la parte de la obra ajena que más se aproxime a su propio gusto o interés. En este 
sentido, el compilador está en todo su derecho de ser guiado por sus particulares preferencias, siempre y cuando se tenga en cuenta que el conjunto de la obra de aquellos autores antologados puede resultar algo muy diferente a lo representado en tal o cual antología bajo su nombre.

Quizás el balance final nos inclina a la convicción de que la antología contemporánea es un producto de la provisionalidad o, en sus mejores ejemplos, de la inestabilidad irreparable dentro de la tradición literaria. Acaso ello sea inevitable. Pero el imponderable de la inestabilidad en el campo del arte, ni por asomo, es un hallazgo de la modernidad, ni siquiera de la posmodernidad (para usar el término acuñado entre otros por Charles Olson en 1949 para designar el estadio del presente). Surgir y perseverar en un entorno adverso ha sido por siempre la más avispada visión de quienes, en todos los tiempos, no han marchado por los caminos convencionales. A la postre la jerarquía de toda autoridad en el campo literario descansa únicamente en la lucidez y perdurabilidad de las ideas detentadas.

Hay que tener en cuenta que la responsabilidad más aportativa del antólogo, dejando a un lado las motivaciones que conduzcan sus intereses inmediatos, no radicaría en sumarse a lo ensalzado sino en detectar, detenerse y recapacitar acerca de lo olvidado. No creer en el canon como algo concluido $y$, por el contrario, reconsiderar permanentemente sus fundamentos. La vocación del antólogo serio (supongamos para el caso que en contados individuos realmente exista tal vocación) nunca finaliza de reformular sus certezas, de reorientar sus opiniones y de ser permeable a sus propias relecturas, pues entiende que su juicio es, a fin de cuentas, una tentativa provisional de llegar a la justicia.

En un clarividente párrafo, el crítico y también poeta José Luis García Martín toca precisamente estas cuestiones y comparte la convicción de que:

Cuando el tiempo pasa, la función del antólogo ya no es distinguir las voces de los ecos, señalar a los verdaderos poetas entre la confusa algarabía de quienes aspiran a conseguir la atención de los lectores, sino impedir que una única voz, o unas pocas voces, tapen a otras igualmente valiosas, aunque quizá no tan sonoras, luchar contra la inercia que limita la riqueza de un tiempo a unos pocos nombres, que son los siempre editados (XIII).

Ante este singular horizonte reaparece, quizá como nunca, el hallazgo y el principal aporte de la antolometría zaideana. Su lección parece hoy más vigente que nunca. leer, estudiar y cuantificar las numerosas antologías que se han multiplicado en nuestros días se ha vuelto predominantemente un ejercicio crítico, comparativo y, en buena medida, estadístico. Pareciera, incluso, que unas a otras discutieran o se corrigieran recíprocamente.

Tal vez para leer el siglo xx (¿acaso el xxi?) algún día habrá que someterlo a un estudio antolométrico general, en el entendido de que, según la máxima atribuida a Abraham Lincoln: Se puede engañar a todo el mundo algún tiempo. Se puede engañar a algunos todo el tiempo. Pero no se puede engañar a todo el mundo todo el tiempo.

De manera que, para cerrar este balance entre los pioneros y los epígonos, se redondea la certeza de que, tanto por su abundancia como por su implícita parcialidad, nadie puede mirar hoy el panorama literario con una sola antología, de la misma manera en que nadie puede conocer una gran ciudad con una guía turística. Aceptemos, pues, el paradigma: todos tienen algo de razón y nadie la tiene del todo.

\section{Relación de antologías, muestras y panoramas de poesía mexicana publicados después de 1980}

(Las entradas se presentan en orden cronológico)

Sandro Cohen. Palabra nueva: dos décadas de poesía en México. México: Premiá, 1981.

Jorge González de León. Poetas de una generación (1940-1949). Prólogo de Vicente Quirarte. México: Universidad Nacional Autónoma de México, 1981.

José Friedl Zapata. Moderne Lyrik aus Mexiko. Stuttgart: K. Thienemanns Verlag, 1984.

Sergio Mondragón. República de poetas. Antología de poesía. México: Martín Casillas, 1985.

Enrique R. Lamadrid y Mario del Valle. Un ojo en el muro I An eye through the wall: Mexican poetry, 1970-1985.

Santa Fe, N. M.: Tooth of Time Books, 1986.

Eduardo Langagne. Con sus propias palabras. Antología de poetas mexicanos nacidos entre 1950 y 1955. Querétaro: Universidad Autónoma de Querétaro, 1987.

Evodio Escalante. Poetas de una generación 1950-1959. México: Universidad Nacional Autónoma de México, Difusión Cultural / Premiá, 1988.

Jean-Clarence Lambert. Poésie du Mexique. Paris: Actes Sud / Unesco, 1988.

Alejandro Sandoval. Ávidas mareas. Breve muestra de la novísima poesía mexicana. México: Instituto Nacional 
de Bellas Artes / Universidad Autónoma de Zacatecas, 1988.

Claude Beausoleil. La poèsie Mexicaine. (Anthologie). Quebec: Écrits des Forges, 1989.

Manuel Ulacia, José María Espinasa y Víctor Manuel Mendiola. La sirena en el espejo. Antología de poesía 1972-1989. Prólogo de Manuel Ulacia y Víctor Manuel Mendiola. México: El Tucán de Virginia / Universidad Nacional Autónoma de México, 1990.

Francisco Serrano. La rosa de los vientos. Antología de poesía mexicana actual. México: Consejo Nacional para la Cultura y las Artes, 1992.

Julio Cu Cortés. Poesía mexicana de la segunda mitad del siglo XX (1940-1990). Antología. México: Universidad Nacional Autónoma de México, 1993.

Yvonne Cansigno. La voz de la poesía en México. Tlaxcala: Universidad Autónoma de Tlaxcala, 1993.

Juvenal Acosta. Light from a nearby window. Contemporary Mexican poetry. Edición bilingüe. Varios traductores. San Francisco: City Lights Books, 1993.

Forrest Gander. Mouth to mouth: Poems by twelve contemporary Mexican women. Prólogo de Julio Ortega. Edición bilingüe. Minneapolis: Milkweed Editions, 1993.

El Grupo Tramontano (Consuelo de Aerenlund, Martha Black Jordan, Jennifer Clement, Brandel France de Bravo, Judith Infante, Margaret Kelly y C. M. Mayo). Ruido de sueños / Noise of dreams. Un panorama de la nueva poesía en México: la generación 1940-1960 / A panorama of the new poetry in Mexico: the 1940-1960 generation. México: El Tucán de Virginia, 1994.

Christopher Domínguez Michael. «Poesía contemporánea de México». La literatura mexicana del siglo XX. México: Consejo Nacional para la Cultura y las Artes, 1995.

Susana González Aktories. Poesía joven de México. Nota preliminar de Hugo Rodríguez-Alcalá. Asunción: Arandurâ Edit., 1995.

Jorge von Ziegler. Poètes Mexicaines Contemporains. Trad. Émile Martel. Quebec: Écrits des Forges / Universidad Nacional Autónoma de México / Aldus, 1996.

Julian Palley. De la vigilia fértil: antología de poetas mexicanas contemporáneas. Irvine: Universidad Nacional Autónoma de México / University of California Irvine, 1996.

José Eduardo Serrato. 10 poetas jóvenes de México. México: Alpe Ediciones, 1996.

Aurora Marya Saavedra. Las divinas mutantes. Carta de relación del itinerario de la poesía femenina en México. México: Universidad Nacional Autónoma de México / Editorial Praxis / Instituto Mexiquense de Cultura / Sociedad General de Escritores de México / Sociedad Exalumnos ESIME del IPN, 1996.
Asunción Horno Delgado. Diversa de ti misma. Poetas de México al habla. México: El Tucán de Virginia, 1997.

Benjamían Valdivia y Demetrio Vázquez Apolinar. De vario México. Guanajuato: Ediciones La Rana / Instituto de Cultura de Guanajuato, 1998.

César Arístides. Bestiario inmediato. Muestra de poesía mexicana contemporánea. México: Ediciones Coyoacán, 2000.

Emilio Fuego y Leticia Luna. Mujeres poetas en el país de las nubes. México: La Cuadrilla de la Langosta / Centro de Estudios de la Cultura Mixteca, 2000.

Agustín Cadena y Gustavo Jiménez Aguirre, Generación del 2000, Literatura mexicana hacia el tercer milenio (poesía, narrativa, ensayo). Prólogo de José Agustín. México: Consejo Nacional para la Cultura y las Artes, 2000.

Hasta agotar la existencia. Antología poética [Sin Firma]. México: Resistencia, 2000.

Juan Domingo Argüelles. Dos siglos de poesía mexicana. Del XIX al fin del milenio: una antología. México: Editorial Océano, 2001.

Claudia Posadas. En el rigor del vaso que la aclara el agua toma forma. Homenaje de poetas jóvenes a Gorostiza. Prólogo de Julio Ortega. México: Resistencia, 2001.

Mónica de la Torre y Michael Wiegers. Reversible monuments, Contemporary mexican poetry. Prólogo de Eliot Weiberger. Edición bilingüe. Varios traductores. Washington: Copper Canyon Press, 2002.

Jen Hofer. Sin puertas visibles, An anthology of contemporary poetry by mexican women. Edición bilingüe. Traducción de Jen Hofer. Pittsburgh: University of Pittsburgh Press / Ediciones Sin Nombre, 2003.

Ernesto Lumbreras y Hernán Bravo Varela (sel., pról., notas y apéndices). El manantial latente, muestra de poesía mexicana desde el ahora, 1986-2002. México: Consejo Nacional para la Cultura y las Artes, 2002.

Rogelio Guedea. Árbol de variada luz, Antología de poesía mexicana actual 1992-2002. Colima: Universidad de Colima, 2003.

Juan Carlos H. Vera. Eco de voces, Generación poética de los sesentas. México: Ediciones Arlequín, 2004.

Alberto Paredes. Una temporada de poesía. Nueve poetas mexicanos recientes (1966-2000). México: Consejo Nacional para la Cultura y las Artes, 2004.

Hasta agotar la existencia II. Antología poética [Sin firma]. Prólogo de Max Rojas. México: Resistencia, 2004.

Tadashi Tsuzumi, Yukata Hosono y Aurelio Asiain. Gendai Mekishiko Shi Shuu. Tokio: Doyobijutsusha Shuppan, 2004.

Miguel Ángel Zapata y Víctor Manuel Mendiola. La coma de la luna. Antología de poesía mexicana 19452003. Estudio preliminar de Miguel Gomes. Bogotá: Común Presencia Editores, 2005. 
Rogelio Guedea y Jair Cortés. A contraluz. Poéticas y reflexiones de la poesía mexicana reciente. México: Consejo Nacional para la Cultura y las Artes, 2005.

Carmina Estrada. Un orbe más ancho. 40 poetas jóvenes (1971-1983). México: Universidad Nacional Autónoma de México, 2005.

Luis Cortés Bargalló y Forrest Gander. Connecting Lines: New Poetry from Mexico. Prefacio de Hernán Lara Zavala, prólogo de Luis Cortés Bargalló. Edición bilingüe, varios traductores. Kentucky: Sarabande Books, 2006.

Víctor Manuel Mendiola, Miguel Ángel Zapata y Miguel Gomes (comps). Tigre la sed. Antología de poesía mexicana contemporánea 1945-2005. Madrid: Ediciones Hiperión, 2006.

Alí Calderón (dir.). La luz que va dando nombre, Veinte años de la poesía última en México 1965-1985. Selección de Alí Calderón, José Antonio Escobar, Jorge Mendoza y Álvaro Solís. Puebla: Gobierno del Estado de Puebla, 2007.

Luis Felipe Fabre. Divino tesoro / Muestra de nueva poesía mexicana. México: Casa Vecina, 2008.

Nosotros que nos queremos tanto. Poesía contemporánea de México. Prólogo de Marcelo Pellegrini. México: El Billar de Lucrecia, 2008.

Luis Alberto Arellano y Román Luján. Le pays sonore. Neuf poètes de la nouvelle poésie mexicaine contemporaine / El pais del ruido. Muestra de poesía mexicana emergente. Quebec: Écrits des Forges / Mantis Editores, 2008.

Susana Cato, Fernando Orduńa y Armando Ponce. 100 poemas mexicanos en papel revolución. México: Secretaría de Educación del Distrito Federal, 2008.

Mario Bojórquez, Alí Calderón, Jorge Mendoza Romero y Álvaro Solís (comps.). El oro ensortijado. Poesía viva de México. México. University of Texas at El Paso, E. U. / Escuela de Letras de la Universidad Mayor de San Marcos, Lima, Perú / Secretaría de Cultura de Puebla, 2009.

Emilio Coco. Antologia della poesia messicana contemporánea. Roma: Sentieri Meridiani Edizione, 2009.

Marco Antonio Campos. La poesía del siglo XX en Mexico. Madrid: Visor, 2009.

Daniel Téllez. Esas distancias de algo. México: Instituto Politécnico Nacional, 2009.

Jorge Esquinca (comp.). Pais de sombra y fuego. Prólogo de José Emilio Pacheco. Guadalajara: Maná / Universidad de Guadalajara / Selva Negra, 2010.

Federico Díaz-Granados (selecc. y pról.). Antología de poesía contemporánea: México y Colombia. Bogotá: Embajada de México en Colombia / Cangrejo Editores, 2011.
Margarito Cuéllar, Mario Meléndez, Luis Jorge Boone y Mijail Lamas (comps.). Vientos del siglo. Poetas mexicanos 1950-1982. México: Universidad Nacional Autónoma de México / Universidad Autónoma de Nuevo León, 2012.

Pedro Serrano y Carlos López Beltrán. 359 Delicados (con filtro). Antología de la poesía actual en México. Santiago de Chile: Ediciones LOM, 2012.

Juan Domingo Argüelles. Antología general de la poesía mexicana. De la época prehispánica a nuestros días. México: Océano, 2012.

Luis Felipe Fabre. La edad de oro, antología de poesía mexicana actual. México: Universidad Nacional Autónoma de México, 2012.

Iván Cruz Osorio. Lumbre en el almaje. Muestra de poesía mexicana (1970-1985). Guatemala: Catafixia Editorial, 2012.

Juan Domingo Argüelles. Antología general de la poesía mexicana. Poesía del México actual, de la segunda mitad del siglo XX a nuestros días. México: Océano, 2014.

Jorge Esquinca, Tedi López Mills y Myriam Moscona. México 20. La nouvelle poésie mexicaine, Prólogo de Philippe Ollé-Laprune, traducción de Jean-Luc Lacarriere y Joani Hocquenghem. Paris: Le Castor Astral / Secretaría de Cultura de México, 2016.

\section{Hemerografía}

José Miguel Ullán. El Paseante. Especial sobre México. Madrid: 1990.

Arturo Trejo Villafuerte. «Nombrar la luz. Voces de la poesía (1950-1968)». Memoria de papel. México. I:2 (octubre 1991).

David Huerta. «El topo en el regazo». Memoria de papel. México. I:2 (octubre 1991).

Reginald Gibbons. "New Writing from Mexico». TriQuarterly Books. EUA. 85 (1992).

Víctor Manuel Mendiola. «Los poetas en México». Cuadernos Hispanoamericanos, dossier La cultura mexicana actual. Madrid. 549-550 (marzo-abril 1996).

Jorge Fernández Granados. «Breve panorama de nuevos ingresos a la poesía mexicana». Viceversa, suplemento Nagara. México. 55 (diciembre 1997).

Jorge Fernández Granados. "Poesía mexicana de fin de siglo: para una calibración de puntos cardinales». Revista de la Universidad de México. México. 576-577 (enero-febrero 1999).

Gustavo Jiménez Aguirre. «Tendencias en la poesía emergente de México (Un nuevo panorama cada día)». Tierra Adentro. México. 100 (octubre-noviembre 1999). 
Adolfo Castañón. «Écrivains du Mexique II». La Nouvelle Revue Française. Paris. 556 (enero 2001).

Claudia Puente. «Diecisiete escalas líricas». El Ángel de Reforma, México. 21 de enero 2001.

Ernesto Lumbreras. «La vigilia del ahora (especulaciones sobre las formas de definir una tradición)». Sábado, de Unomásuno. México. 1236 (9 de junio 2001).

Marco Lucchesi. «Poesia mexicana hoje». Poesia Sempre. Río de Janeiro. 15 (noviembre 2001).

Catharina Blauwendraad. «Mexiko nummer». De Twede Ronde. Amsterdam. 23:1 (primavera 2002).

Reynaldo Jiménez. «Nitidez abisal: 23 poetas mexicanos». tsé-tsé. Buenos Aires. 11 (2002).

Alfonso Alegre y Victoria Pradilla. «La X en la frente, México en la poesía». Rosa cúbica. Barcelona. 23-24 (invierno 2002-2003).

Juan Alcántara (presentación). «Once nuevos poetas mexicanos». El poeta y su trabajo. México. 14 (invierno 2003).

Alí Calderón. «La palabra es un tigre en el pastizal del ojo. La generación poética de los setenta». Biblioteca de México. México. 90 (noviembre-diciembre 2005).

Mario Bojórquez y Jair Cortés. «Muestra de poesía mexicana 1964-1985». Blanco móvil. México. 101 (primavera 2006).

Alí Calderón e Iván Cruz Osorio. «En el vértigo de los aires. Poetas de la década de 1980». Alforja. México. 37 (verano 2006).

Gilberto Prado Galán (coord.), «Número sobre poesía mexicana contemporánea». RevistAtlántica de poesía. Cádiz. 30 (otońo 2006).

"Homenaje oportuno a la poesía mexicana» [sin firma]. Estafeta del viento. Madrid. 9/10 (invierno 2006).

«Poesía» [sin firma]. Tierra Adentro. México. 145 (abrilmayo 2007).

Jacobo Sefami. «Mexican poetry today». Poetry International. San Diego: San Diego State University. 11 (2007).

José Ángel Leyva, Eduardo Langagne y Ana Franco Ortuño. «Literatura mexicana actual: entre el Norte y el Sur». Fórnix. Lima: 8/9 (octubre 2008).

Mario Meléndez (selección) y Jorge Mendoza Romero (prólogo). «24 poetas mexicanos». Casa del Tiempo. México. (octubre 2009). [Esta muestra se ha publicado, con progresivas variantes, en diversos medios electrónicos. Ómnibus. Medio de publicación (web). <http://www.omni-bus.com/n28/24poetas.html>. Consultado 23 oct. 2016.]

«Novísima poesía mexicana / Up-and-coming Mexican Poets». Edición bilingüe. Reverso. Guadalajara. 18:9 (noviembre-diciembre 2009).
Antonio Jiménez Millán y Álvaro Salvador. «México. Literatura y arte contemporáneos». Litoral, Revista de poesía, arte y pensamiento. Málaga. 251 (1er semestre 2011).

\section{Medios digitales}

Malva Flores, Gustavo Jiménez Aguirre y Rodolfo Mata. Horizonte de poesía mexicana. 1997. Horizonte. UNAM. Medio de publicación (web). <http://www. horizonte.unam.mx/>. Consultado 28 oct. 2016.

Elías Nandino, Salvador Encarnación y Javier Ponce. Antología de la poesía mexicana del siglo XX. S. f. Fuentes. UDG. Medio de publicación (web). <http:// fuentes.csh.udg.mx/CUCSH/argos/antologi/index. htm>. Consultado 27 sept. 2018.

Raquel Huerta Nava. La pléyade. Antología de la novisima poesía. 1998. Oocities. Medio de publicación (web). <http://www.oocities.org/cocodril.geo/antolog.html>. Consultado 28 oct. 2016.

Blanca Orozco de Mateos. Palabra Virtual. 2006. Palabra Virtual. Medio de publicación (web). <https://palabravirtual.com/>. Consultado 28 oct. 2016.

Carlos Adolfo Gutiérrez Vidal. Contemporary Mexican poets. S. f. Thing. Medio de publicación (web). <http:// www.thing.net/ - grist $/ 1 \& d /$ mex.htm $>$. Consultado 28 oct. 2016.

Rodrigo Castillo (coordinador y editor del sitio). Las afinidades electivas / Las elecciones afectivas. México. 2006. Las elecciones afectivas. Medio de publicación (web). <http://laseleccionesafectivas-mexico.blogspot. com/>. Consultado 28 oct. 2016.

\section{Bibliografía}

Argüelles, Juan Domingo. Antología general de la poesía mexicana. Poesía del México actual, de la segunda mitad del siglo XX a nuestros días. México: Océano, 2014.

Cordero, Sergio. «Herbert: un caníbal que muerde el rebozo». La humildad premiada. Saltillo: Universidad Autónoma de Coahuila. Nueva época, año VIII: 13-14 (diciembre 2011): 49-55.

García Martín, José Luis. «Incluir y excluir. La revisión del canon». Poetas del novecientos, t. I. Madrid: Fundación BSCH, 2001: IX-XXIII.

Gordon, Samuel. «Breve atisbo a la poesía mexicana de los ańos setenta y ochenta». Revista de Literatura Mexicana Contemporánea. Texas: The University of Texas at El Paso, 17 (marzo 2002): 7-17. Retomado y ampliado luego en «Breve atisbo metodológico a 
la poesía mexicana de los años setenta y ochenta». Samuel Gordon (comp.). Poesía mexicana reciente: aproximaciones criticas. México: Eón / The University of Texas at El Paso, 2005: 105-126.

Higashi, Alejandro. «Hitos provisionales en el perfil de una generación: poetas mexicanos nacidos entre 1975 y 1985». Literatura Mexicana, 25:2 (2014): 49-74. Disponible en <http://www.sciencedirect.com/ science/article/pii/S0188254614726121> [última consulta: 27 de septiembre de 2018].

Higashi, Alejandro. PM/XXI/360 ${ }^{\circ}$. Crematística y estética de la poesía mexicana contemporánea en la era de la tradición de la ruptura. México: Tirant Humanidades / Universidad Autónoma Metropolitana, 2015.

Mendiola, Víctor Manuel. «La crítica y las becas». Laberinto de Milenio Diario. México, 28 de agosto, 2010: s. p.

Monsiváis, Carlos. «No sin nosotros»: los días del terremoto 1985-2005. México: Era / Ediciones LOM / Trilce / Txalaparta, 2005.
Ramírez, Israel. "Treinta años de poesía en México: 1980-2010, dos acercamientos, múltiples preguntas». Rogelio Guedea (coord.). Historia critica de la poesía mexicana II. México: Fondo de Cultura Económica / Consejo Nacional para la Cultura y las Artes, 2015: 437-467.

Ruiz Casanova, José Francisco. Anthologos: poética de la antología poética. Madrid: Cátedra, 2007.

Serrano, Pedro y Carlos López Beltrán (comps.). 359 Delicados (con filtro). Antología de la poesía actual en México. Santiago de Chile: Ediciones LOM, 2012.

VITAL, Alberto. La cama de Procusto (Vanguardias y polémicas, antologías y manifiestos, México 1910-1980). México: Universidad Nacional Autónoma de México, 1996.

ZAID, Gabriel (comp.). Asamblea de poetas jóvenes de México. México: Siglo xxi, 1982 [ed. or. 1980]. 